\title{
Huge mucinous cystadenoma of ovary in a reproductive female: an enigma
}

\section{Kanchan Digambar Bhoyar ${ }^{1}$, Sakshi Abhinav Zawar ${ }^{1}$, Abhijit Sharachandra Ambike ${ }^{1 *}$, Unmesh Sureshrao Santpur', Vijay Dhundiraj Dombale ${ }^{2}$}

\begin{abstract}
${ }^{1}$ Department of Obstetrics and Gynecology, ${ }^{2}$ Department of Pathology, BKL Walawalkar Rural Medical College, Derwan, Maharashtra, India
\end{abstract}

Received: 09 August 2021

Revised: 14 September 2021

Accepted: 15 September 2021

\section{*Correspondence:}

Dr. Abhijit Sharachandra Ambike,

E-mail: aambike@gmail.com

Copyright: () the author(s), publisher and licensee Medip Academy. This is an open-access article distributed under the terms of the Creative Commons Attribution Non-Commercial License, which permits unrestricted non-commercial use, distribution, and reproduction in any medium, provided the original work is properly cited.

\begin{abstract}
To report the occurrence of a rare case of a huge benign ovarian tumour (mucinous cystadenoma) in in a tertiary care rural teaching hospital in Konkan, Maharashtra, India. Our reported case was a young woman of reproductive age group which was very rare who presented with marked abdominal distension and discomfort at the obstetrics-gynaecology OPD of BKL Walavalkar rural medical college. The data were collected by history-taking, clinical examination, laboratory investigations, transabdominal ultrasonographic examination and by histopathological study of the excised surgical specimen. The case was reported as a rare massive ovarian mucinous cystadenoma in a woman of reproductive age group. This case report emphasized the significance of thorough evaluation of all women presented with vague abdominal pain and gradual abdominal distension in reproductive age group. Although the condition is extremely rare, women from rural area neglect such conditions and present late which may pose challenges in the management.
\end{abstract}

Keywords: Mucinous, Cystadenoma, Laparotomy, CA12

\section{INTRODUCTION}

Ovarian cystadenomas are benign tumours which arise from the surface epithelium of the ovary. They are multilocular with smooth outer and inner surfaces. They tend to grow to massive proportions. Of all ovarian tumours, mucinous tumours comprise $15 \% .^{1,2}$ About $80 \%$ of mucinous tumours are benign, $10 \%$ are borderline and $10 \%$ are malignant. Although benign ovarian mucinous tumours are rare at the extremities of age, before puberty and after menopause they are common between the third and the fifth decades. ${ }^{3,4}$

The most frequent complications of benign ovarian tumour, in general, are torsion, haemorrhage and rupture. As it contains mucinous fluid, its rupture leads to mucinous deposits on the peritoneum (pseudo-myxoma peritonei). This report presented a case of a giant ovarian mucinous cystadenoma in a reproductive age woman.

\section{CASE REPORT}

A 29 year old female patient, P2L2, tubectomised with gradual distension of abdomen and feeling of discomfort and fullness since three years (Figure 1). Patient also had history of altered bowel habits since last 3 years. There was no history of pain in abdomen, no history of menorrhagia or abnormal $\mathrm{p} / \mathrm{v}$ bleeding and no dyspareunia. The age of menarche was 13 years with no menstrual abnormalities. Obstetric history was married since 8 years, two previous LSCS done for failed induction of labour. Laparoscopic tubal ligation done 3 years back. Past family and personal history not contributory. 


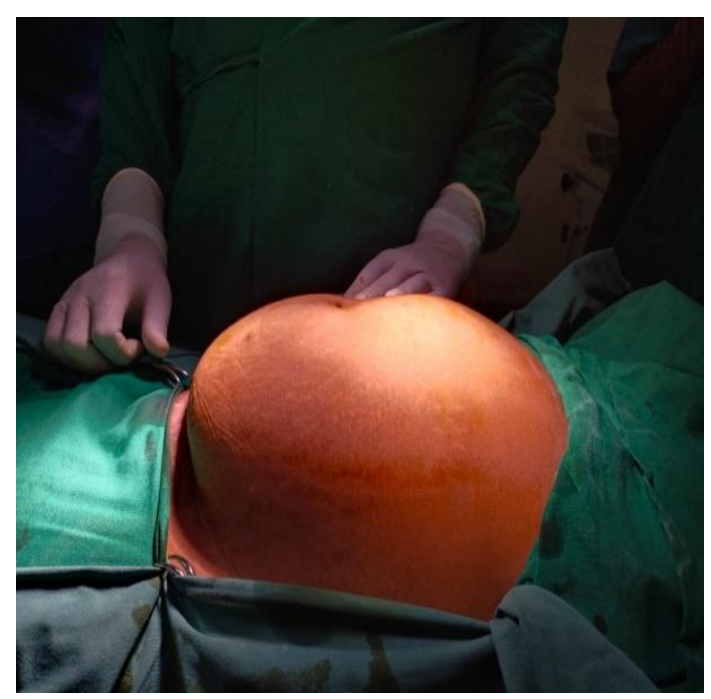

Figure 1: Preoperative P/A view.

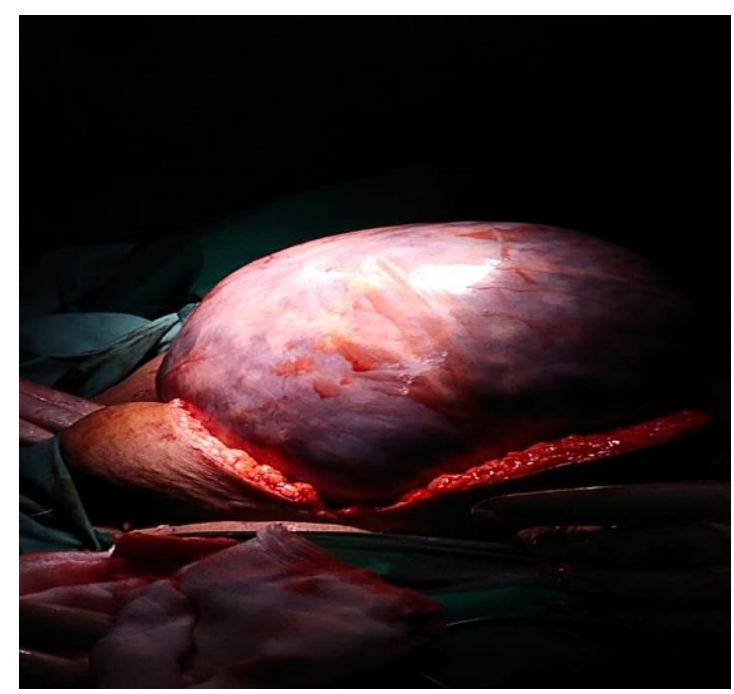

Figure 2: Exposing the cyst after incision.

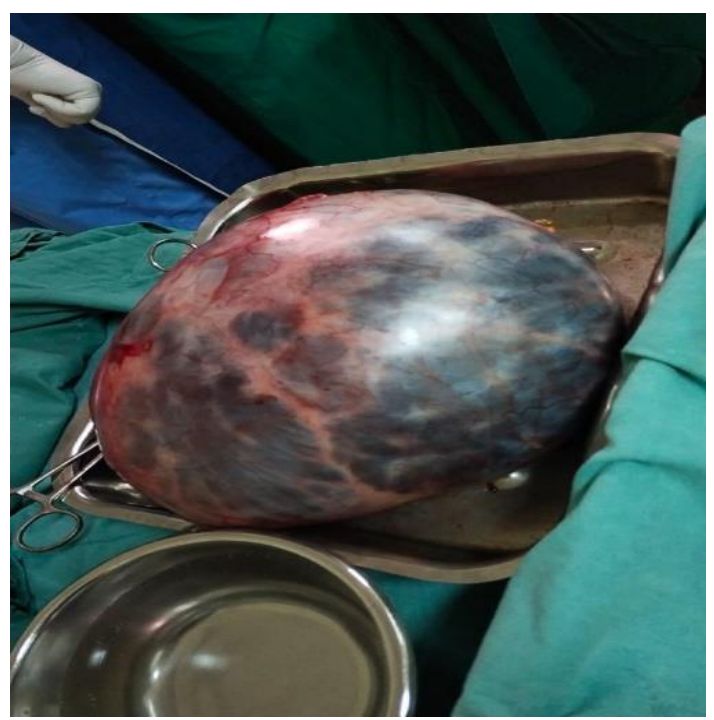

Figure 3: Huge bluish grey cyst in the tray excised.

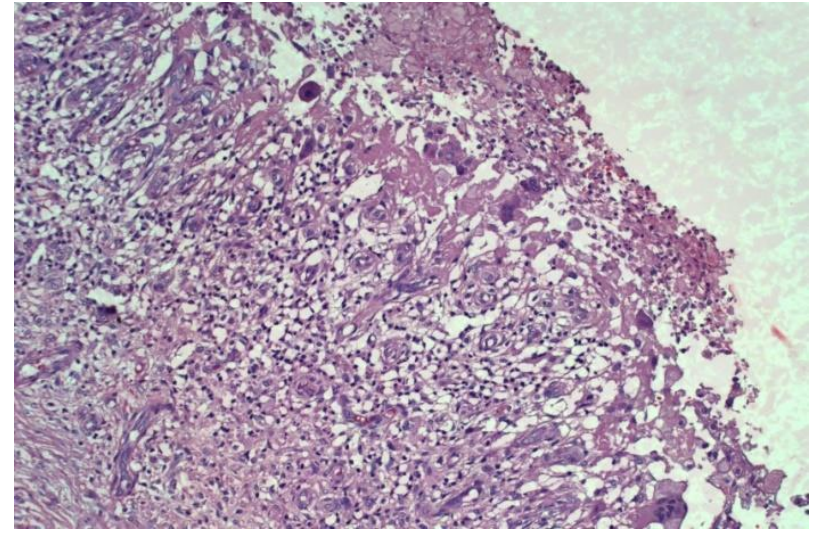

Figure 4: H/P report; large mucinous cells.

G/E: all vitals stable; P/A: pfannenestiel scar was+which was healthy. Abdo distended to 32 weeks' gravid uterus size. The mass was mobile, non-tender. No ascites; P/S: vagina and cervix were healthy; $\mathrm{P} / \mathrm{V}$ : there was fullness in the right fornix; uterus was normal size, anteverted and no nodules or mass felt in the pouch of Douglas.

Ultrasound examination of abdo pelvis revealed a welldefined large oval shaped cystic lesion $24 \times 12 \times 22 \mathrm{cms}$ showing posterior acoustic shadow. Right ovary was not seen separately from this lesion. Multiple internal echoes were noted in this lesion. It showed peripheral vascularity on color Doppler imaging. Lesion compressed right lower ureter causing mild hydronephrosis and hydroureter on right side, there was no calcification noted within the lesion. Left ovary appeared normal. Features were suggestive of large right ovarian cystadenoma, there was no evidence of free fluid in the abdomen, pelvis and POD. No pre and paraaortic lymphadenopathy was noted.

$\mathrm{CT}$ abdomen pelvis confirmed the above findings. Tumor marker study revealed beta-HCG was $1.20 \mathrm{Miu} / \mathrm{ml}$, CA125 was $30.2 \mathrm{U} / \mathrm{ml}$, CA-99 was $4.93 \mathrm{U} / \mathrm{ml}$, CEA was 2.24 $\mathrm{ng} / \mathrm{ml}$.

Explorative laporotomy with right ovarian cystectomy was done under general and epidural anaesthesia. The intraoperative findings were as follows: a huge ovarian mass of size $24 \times 12 \times 22 \mathrm{cms}$ was arising from right ovary (Figure 2). It was bluish white in colour and solid to cystic in consistency, surface was smooth (Figure 3). There was no ascites. The omentum was normal. There were no deposits anywhere in the peritoneal cavity. The under surface of the liver and diaphragm was normal. Patient had uneventful recovery and was discharged on the 8th day postoperative after suture removal. Sample was sent for histopathology which suggested diagnosis of mucinous cyst adenoma of the right ovary (Figure 4).

\section{DISCUSSION}

Massive ovarian tumours have become a rarity in current medical practice as most cases are discovered early at routine check-ups. Mucinous cystadenoma is a benign 
ovarian tumour. It was reported to occur in middle-aged women. On gross appearance, mucinous tumours were characterised by cysts of variable sizes without surface invasion. These tumors were usually evaluated using ultrasound, CT scan, MRI. These ovarian tumor may be multiseptated, cystic masses with thin walls. They may contain varying amount of solid tissue which consist of proliferating stromal tissue, papillae or tumor malignant cells. Tumor marker helped us to detect origin of tumour. Mucinous cystadenoma were divided in three categories, benign, borderline and malignant. Survival was largely dependent on the histology of the tumor, with a 10 year survival rate of $100 \%$ for benign tumors, $60 \%$ for borderline tumors and only $34 \%$ for the malignant subtype. Modern methods of investigation particularly ultrasonography can identify the nature of the tissue as in this case. A lining of tall columnar epithelia cells with apical mucin and the absence of cilia histologically characterize benign mucinous tumours.

The management of ovarian cystadenomas depended on the following factors: symptoms, size of the cyst, age of the patient, medical history and menopausal state of the patient.

Unilateral salpingo-oophorectomy or ovarian cystectomy was the adequate treatment of ovarian cystadenomas. ${ }^{5}$ Clinical recurrence was uncommon and reflected either incomplete resection or a new primary tumor. ${ }^{6}$ In our case, the tumour was unilateral, affecting the right ovary. In our patient, right salpingo-oophorectomy was performed as there was no ovarian tissue left and the tube was stretched and elongated over the cyst. After surgery, the patient should be followed-up carefully as there was a tendency to recur. Although the tumour was removed completely and intact with the affected ovary, our patient was suggested follow up at regular intervals.

\section{CONCLUSION}

Our patient was in the reproductive age group with this huge mucinous cystadenoma which is a very rare finding in Indian literature, hence the need of reporting. This case report emphasizes the significance of thorough evaluation of all women presented with vague abdominal pain and gradual abdominal distension in reproductive age group. Although the condition is extremely rare, women from rural area neglect such conditions and present late which may pose challenges in the management.

Funding: No funding sources

Conflict of interest: None declared

Ethical approval: Not required

\section{REFERENCES}

1. Vizza E, Galati GM, Corrado G, Atlante M, Infante C, Sbiroli C. Voluminous mucinous cystadenoma of the ovary in a 13-year-old girl. J Ped Adoles Gynecol. 2005;18(6):419-22.

2. Mittal S, Gupta N, Sharma A, Dadhwal V. Laparoscopic management of a large recurrent benign mucinous cystadenoma of the ovary. Arch Gynecol Obstet. 2008;277(4):379-80.

3. Crum CP, Lester SC, Cotran RS. Pathology of female genital system and breast. In: Kumar V, Abbas A, Fausto N, Mitchell R, eds. Robbins' Basic pathology. USA: Elsevier; 2007.

4. Ioffe OB, Simsir A, Silverberg SG. Pathology. Practical Gynaecologic Oncology. In: Berek JS, Hacker NF, eds. Philadelpjia: Lippincott Williams and Wilkins; 2000: 213-4.

5. Katke RD. A huge ovarian mucinous cystadenoma $(8.5 \mathrm{~kg})$ leading to bilateral hydronephrosis: a case report and review of literature. MOJ Clin Med Case Rep. 2017;7(1):166-8.

6. Alobaid AS. Mucinous cystadenoma of the ovary in a 12-year-old girl. Saudi Med J. 2008;29(1):126-8.

Cite this article as: Bhoyar KD, Zawar SA, Ambike AS, Santpur US, Dombale VD. Huge mucinous cystadenoma of ovary in a reproductive female: an enigma. Int J Reprod Contracept Obstet Gynecol 2021;10:4014-6. 